Portland State University

PDXScholar

1981

\title{
Transparent sculptures, lithographs, and watercolors : a personal response to the natural world
}

Stephan Spencer Soihl

Portland State University

Follow this and additional works at: https://pdxscholar.library.pdx.edu/open_access_etds

Part of the Art Practice Commons, and the Sculpture Commons

Let us know how access to this document benefits you.

\section{Recommended Citation}

Soihl, Stephan Spencer, "Transparent sculptures, lithographs, and watercolors : a personal response to the natural world" (1981). Dissertations and Theses. Paper 3133.

https://doi.org/10.15760/etd.3127

This Thesis is brought to you for free and open access. It has been accepted for inclusion in Dissertations and Theses by an authorized administrator of PDXScholar. Please contact us if we can make this document more accessible: pdxscholar@pdx.edu. 
TRANSPARENT SCULPTURES, LITHOGRAPHS, AND WATERCOLORS:

A PERSONAL RESPONSE TO THE NATURAL WORLD

by

STEPHAN SPENCER SOIHL

A Thesis Report Submitted in Partial Fulfillment

of the Requirements for the Degree of

MASTER OF FINE ARTS

in

SCULPTURE

Portland State University, 1981 
TO THE DEPARTMENT OF ART AND ARCHITECTURE:

The Members of the Thesis Committee Approve the Thesis and Report of Stephan Spencer Soihl presented March 2, 1981.

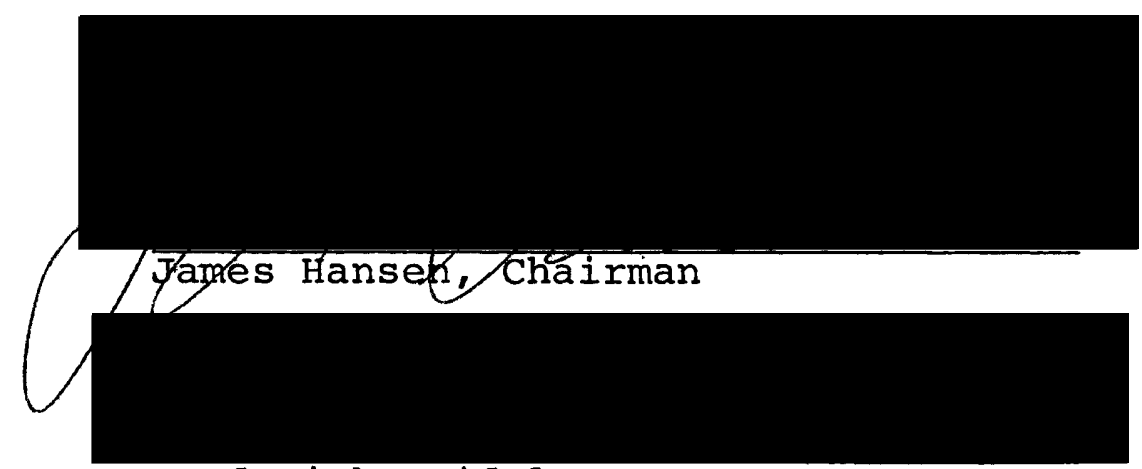

Frederick Heidel

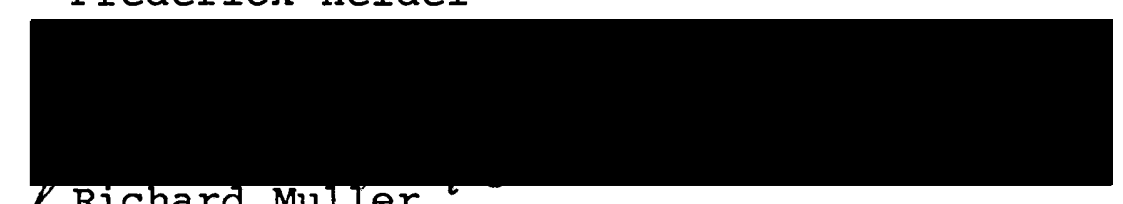

$\gamma$ Richard Muller

Michihiro Kosuge

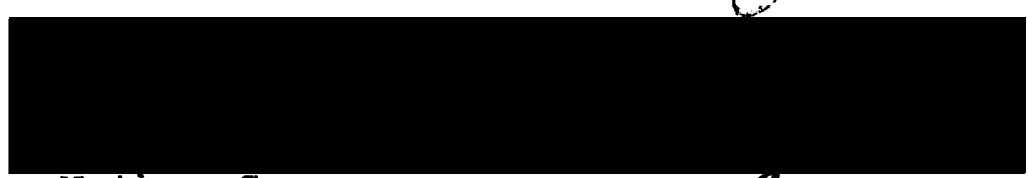

Nathan Cogan

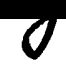

APP ROVED :

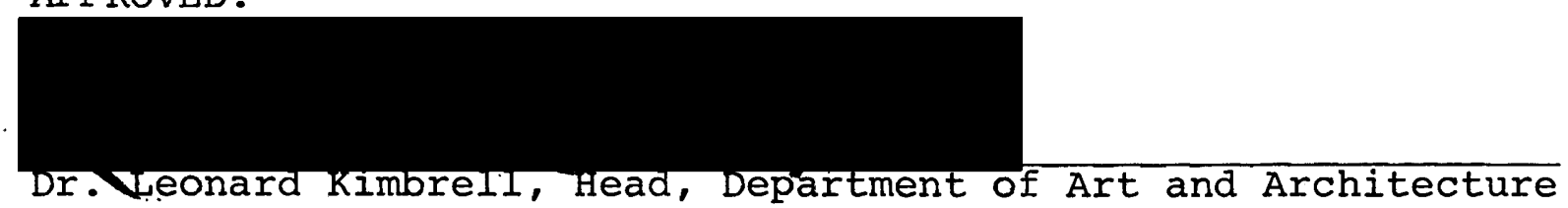


The group of works that I am presenting as my Master of Fine Arts thesis exhibition is a selection of my best work from the past three years. It is made up of two different artistic forms: fairly small sculptures comprised of aluminum channel and plexiglas, on the one hand, and lithographs and watercolors, on the other.

These two different forms do not necessarily represent disparate ways of working. Indeed I will show that there are significant similarities despite obvious differences in the media involved. When I talk about the lithographs later in this paper, I will explore the issues of the interconnections. Specifically I will comment on the emotional responses these two forms evoke.

What is most significant to my thesis is the importance of the sculpture. clearly any discussion of my work must focus upon and emphasize not only the created work but also, more importantly, the process underlying these ways of working. Another consideration is the overall impression the total installation makes on the viewer. I feel these twoand three-dimensional ways of working enhance each other, especially since color plays such an important part in both. 
The content of the sculptures is very abstract and very formal. Pure forms are to be appreciated in their own right. The interaction of these forms with each other and the way they change with time are of great importance. Thus the key concept upon which the sculptures are based is that they are not static, but rather kinetic.

There are, in fact, two somewhat separate concepts implicit here within the overall idea of the kinetic. One idea is that colored shapes can actually be seen to be moving, enlargening or diminishing as volumes fill or empty. The other is that the sculpture is different at various times: indeed when the viewer returns to it it has changed, perhaps only slightly or perhaps a great deal.

The sculptures are made up of volumes or chambers capable of holding liquids, which in turn have different colors. Rather than merely being stationary within the volumes, the liquids can be moved around by means of tubing and pumps. The liquids within the volumes make shapes smaller than the volumes themselves. Hence these shapes change as the liquids move.

It is also intended that there be some degree of separation or distance between these variously colored volumes so that there is some feeling of space within the piece itself; in other words, that small slabs of color are positioned at various points within a space that is the domain of the 
sculpture. A related concept is that these colored volumes are also transparent. If this is the case, then one volume can be perceived through another. In fact, the visual effect of the volumes can be heightened as their colors add. The simplest volumes that can be made are rectangular. Or perhaps I should say the simplest use of materials in fabricating volumes leads to rectangular ones. It is possible, however, to introduce a tilted or diagonal line, either on the outside edge of a volume with a trapizoidal shape resulting, or within a volume itself, so that more than one shape is formed by the liquid. This off-vertical line does, in fact, begin to give the sculptures something more in common with the two-dimensional work in the thesis project. This idea I'll elucidate a bit more farther on in the paper. 


\section{THE SCULPTURES:}

\section{A HISTORY OF THEIR DEVELOPMENT}

Before beginning the Master of Fine Arts program at Portland state University I had completed two small sculptures in which transparent chambers made of plexiglas and aluminum channel were positioned one behind another in three rows. The chambers, rectangular in shape, were partially filled with dyed water, which moved up and down as a set of auxiliary chambers rotated about an axis on the wall. These sculptures were an outgrowth of polyester resin pieces which were formally composed of many parallel bands of color arranged vertically within a thick, transparent slab. (I had made this change in my way of working from the resin to the dyed water, partly for the sake of my health: I could at times feel the effects of the resin in my throat and upper lungs.) For my thesis project I wished to continue developing the pieces based on the separate chambers and to explore to a considerable degree various ideas for sculpture within this general way of working.

During my first year in the program a much larger piece was done which relied on the same principles as the earlier, smaller pieces. Three chambers, 42 inches high, were placed one behind another and were connected by tubing to a set of rotating chambers attached to the wall.

At the end of the first year when I defended my thesis proposal, members of the committee raised questions about 
the tubing which hung--one might say dangled--between the two sets of chambers. One set was the primary part of the sculpture and was placed on the stand and the other set rotated about an axis on the wall nearby. The manner in which this tubing hung varied, of course, with the position of the wall piece and had a certain randomness or uncontrolled quality to it. Also, with all these pieces it was understood that the viewer would manually rotate the set of chambers on the wall; indeed, a handle was provided for that purpose. Of course I had no way of knowing about or controlling the manner in which the viewer would interact with or activate the pieces, and to this point there was some concern expressed as well. I myself was somewhat in agreement with this criticism of the work, especially with the question of the manner in which the tubing dangled and swayed. So at the end of my first year in the program I felt obliged to try to deal with these criticisms. I also felt the inclination to enrich or expand upon the basic ideas of the sculptures with each new piece. One further problem emerged. I became particularly aware that the dyed water, in a few weeks, would form a residue within and on the sides of the chambers, because constituents of the water and dye decomposed and as the water picked up dust from the air.

At this point I had the idea of using oil rather than water as the liquid which moved up and down in the chambers. I realized that the range of colors I would work with would probably be severely limited, since motor oils, transmission 


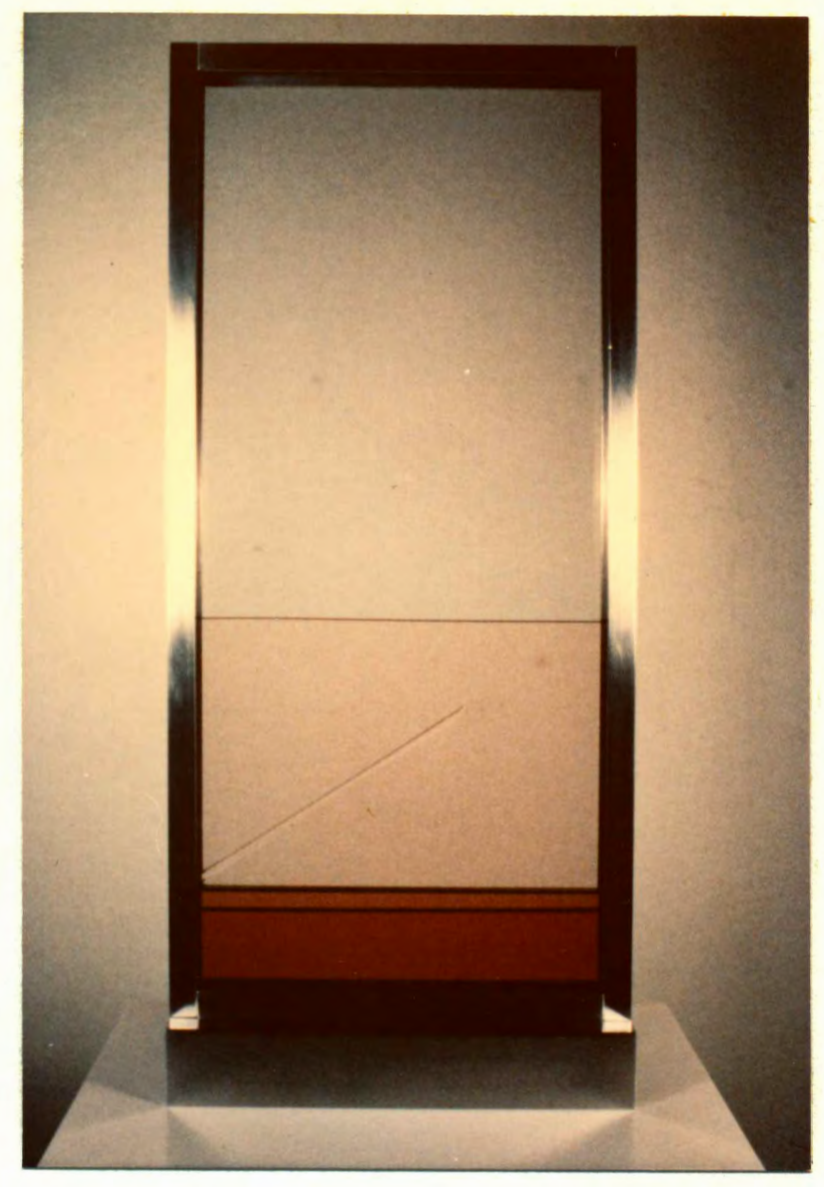

Figure 1

fluids, etc., that could be readily purchased were all of red, orange, or yellow hue. But I was aware of the fact that oils can remain in containers for years with no apparent change in their condition. After I decided to cap each chamber with the same aluminum channel that formed the other three sides in order to keep the dust out, I found the visual result to my liking. It seemed that the sculpture now had more of a sense of completeness to it.

The issues of the dangling tubing and the randomness of viewer participation, as well as the necessity of building a set of auxiliary chambers for each piece, could be eliminated, I realized, by installing pumps and a timer hidden from view 
within the base or stand for each piece.

This solution appealed to me very much. I put away pieces I had been working on (since the large, three-chambered piece) and began a new piece which, from the beginning, was conceived with a pump and timer in mind (Fig. 1). In this piece I also evolved the concept of just one rectangular set of larger aluminum channel forming the framework for several chambers, identical except for their thickness, and positioned directly behind one another, all held together and in place by the sections of channel. I envisioned one timer and one pump, thus one color. The oil would flow from one chamber to another through little holes hidden at the sides of the piece behind the edge of the channel, and there would be some color change due to the differences in the thickness of each chamber (actually value change which, in transparent materials, results in a degree of color change).

I found, however, that the correct installation of the pump and timer and all the other apparatus, tubing, fittings, a valve, wiring, etc., was no small feat. I wanted a system that could be partly dismantled when the sculpture was moved and then be put back together again and function. And it was imperative that there be no leakage of the oil.

I also felt I could reasonably expect these sculptures to operate for years if sufficient care was taken in their planning and construction. In other words, a certain standard of "engineering" quality was necessary in order to allow them a fairly long lifetime of operation. I mention the following 


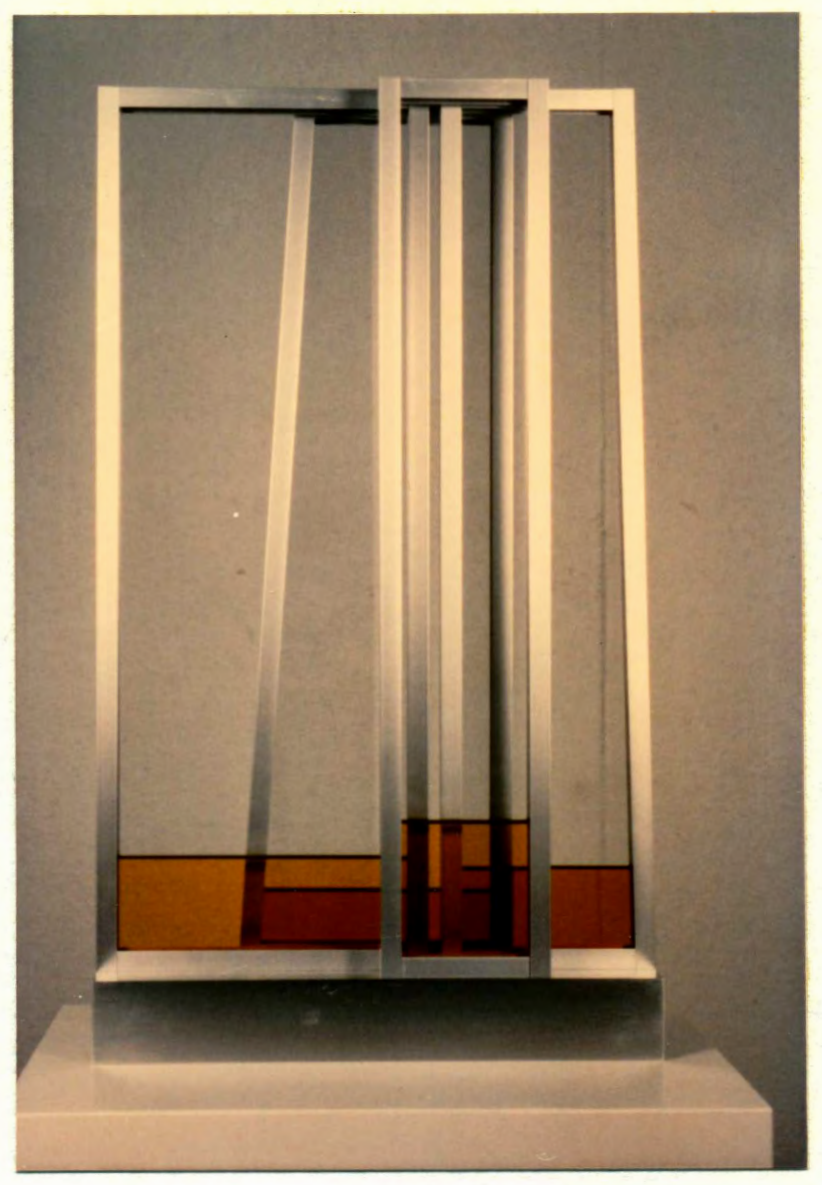

Figure 2

in order to give an example of what can go wrong which, in turn, can jeopardize the life of the sculpture or at least make necessary a major dismantling and clean-up.

The oil enters the thicker middle chamber from a reservoir placed below the piece in the stand, through a hole in the bottom middle of the rubber seal and through the aluminum of the channel and base. A short piece of copper tubing is the actual passageway, with one end fitted into the rubber seal and the other end fitted into plastic tubing which leads to the pump. I discovered, to my dismay, that although the copper tubing is fitted snugly into the rubber seal, it can 
be pulled out, for instance durina the removal of the sculpture from its. stand: what results is oil flowing between the rubber seal and the channel and eventually leaking out onto the base. There is a fairly obvious way to insure that this does not happen. I used a piece of tubing with a flared end or flange instead of an ordinary piece of tubing; and I found it was necessary to insert it into the rubber seal from the inside of the sculpture before the pieces of plexiglas and rubber are assembled within the aluminum channel.

The two earliest pieces in the thesis project were, in a sense, conceived of as a pair or as companion pieces (Figs. 2-3). The idea was that both pieces would each have four chambers. Eight chambers were constructed, with the objective that there be considerable variety among them. Hence some were quite broad, some were as narrow as could feasibly be constructed, and some were of a size in-between. Two chambers were made trapizoidal in shape, that is, one of the sides was inclined inward from the vertical. There was a different angle of inclination for the two as well. Once the eight chambers were constructed, I began to arrange them into two sets or sculptures, each with three rows. At this point I was composing the sculpture out of shapes already made. Many possibilities were considered and of course I needed a good solution for both of the sets at the same time. The two simultaneous solutions I liked best perhaps could not have been anticipated while constructing the volumes 


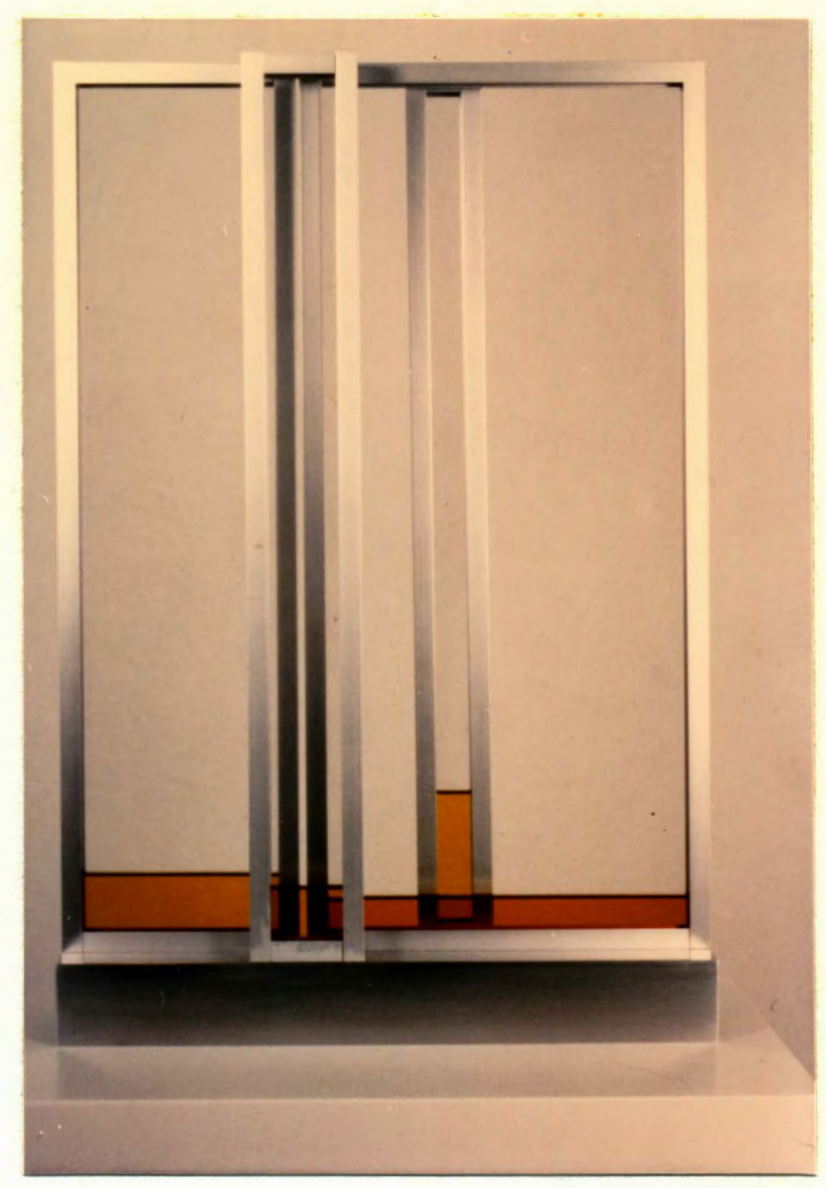

Figure 3

themselves: the two trapizoidal shapes were placed in the same piece and the broadest and thinnest volumes were also put together in the other piece. This solution seemed to provide the most variety, seemed to be the most exciting and visually challenging arrangement.

Another idea came to me about this time but it was several months before I saw the idea through to a state of completion. The idea was that instead of making the usual volume of a rectangular shape one could place two volumes, two rectangles, one above the other vertically within the overall shape (Fig. 4). In order to raise and lower the oil in the upper volume, small plastic tubing would have to 


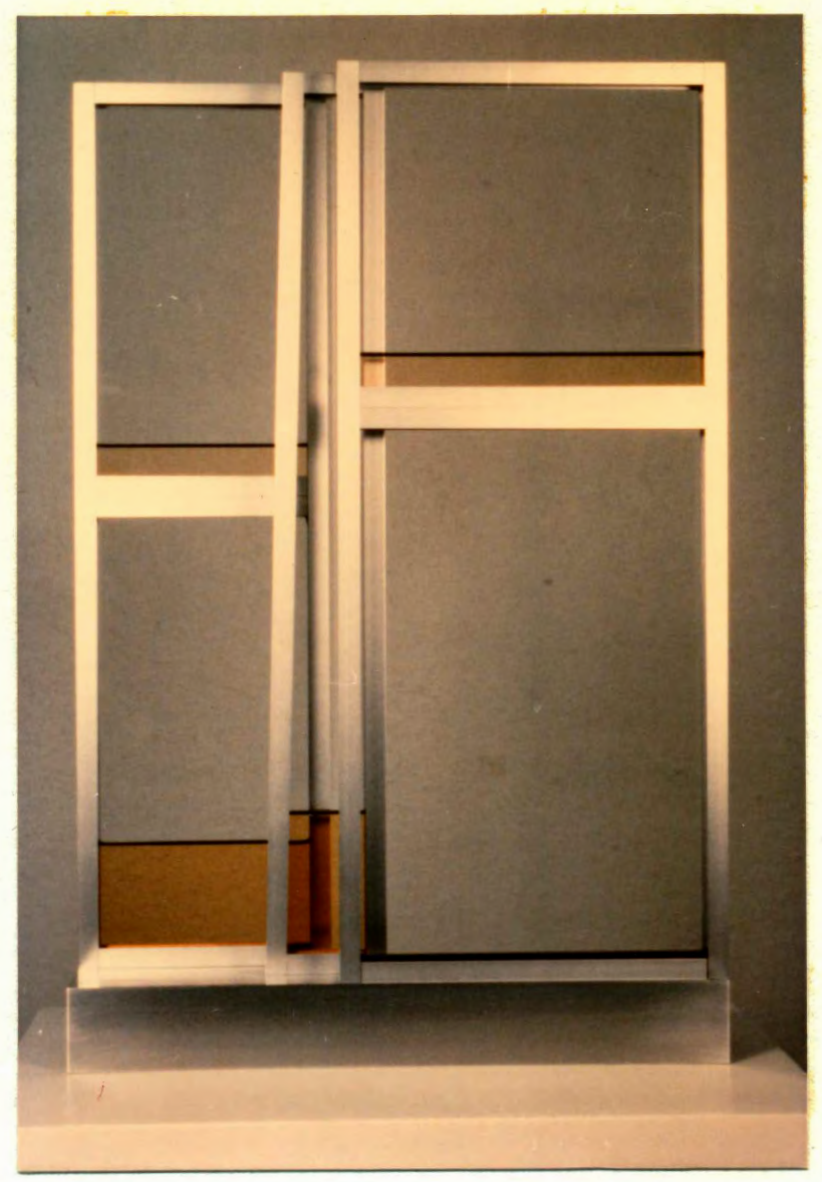

Figure 4

make its way up the side of the chamber, hidden from view within the aluminum channel. Horizontally, between the two volumes, there would be a band of the channel which would be a double width, one piece for the upper volume and one piece for the lower. (It should be explained that the channel is always necessary on all sides of a chamber in order to form a seal: between the two plexiglas sides and an inner aluminum strip are rubber seals, all of which are held very tightly in place by the sides of the channel.) This double width of channel, placed horizontally, has had quite an effect compositionally, contrasting with the upwardly 
moving, vertical sense of the aluminum chamber sides.

It seemed that having made one of these double chambers it would be appropriate to make a second double chamber for the sculpture. The question was at what height to place the dividing band in the second double chamber. I also decided that it would be appropriate to make a single narrow chamber and have it be slightly trapizoidal. The presence of this shape would then give the sculpture something more in common with the first two sculptures. What was particularly interesting to me about the double chambers was that in the first place there could be two colors of oil in one chamber and in the second place the upper chamber, when it began filling, would provide a color at a considerable height above the base of the sculpture and above an area of clear plexiglas in the lower chamber. This was in contrast to the usual situation in which all colors rose up out of the base.

Another development in the progression of my sculptural ideas now merits discussion. I have mentioned the piece which had the leakage problem, the piece which was constructed out of a single set of larger channel, with three chambers formed by four pieces of plexiglas of the same size (see Fig. 1). The chambers were exactly the same except for their thickness, and it would be difficult for a viewer to tell how many of them there were and how thick they were, until they had oil in them. As the oil rose up in the thicker center chamber, the level in the thinner outer 


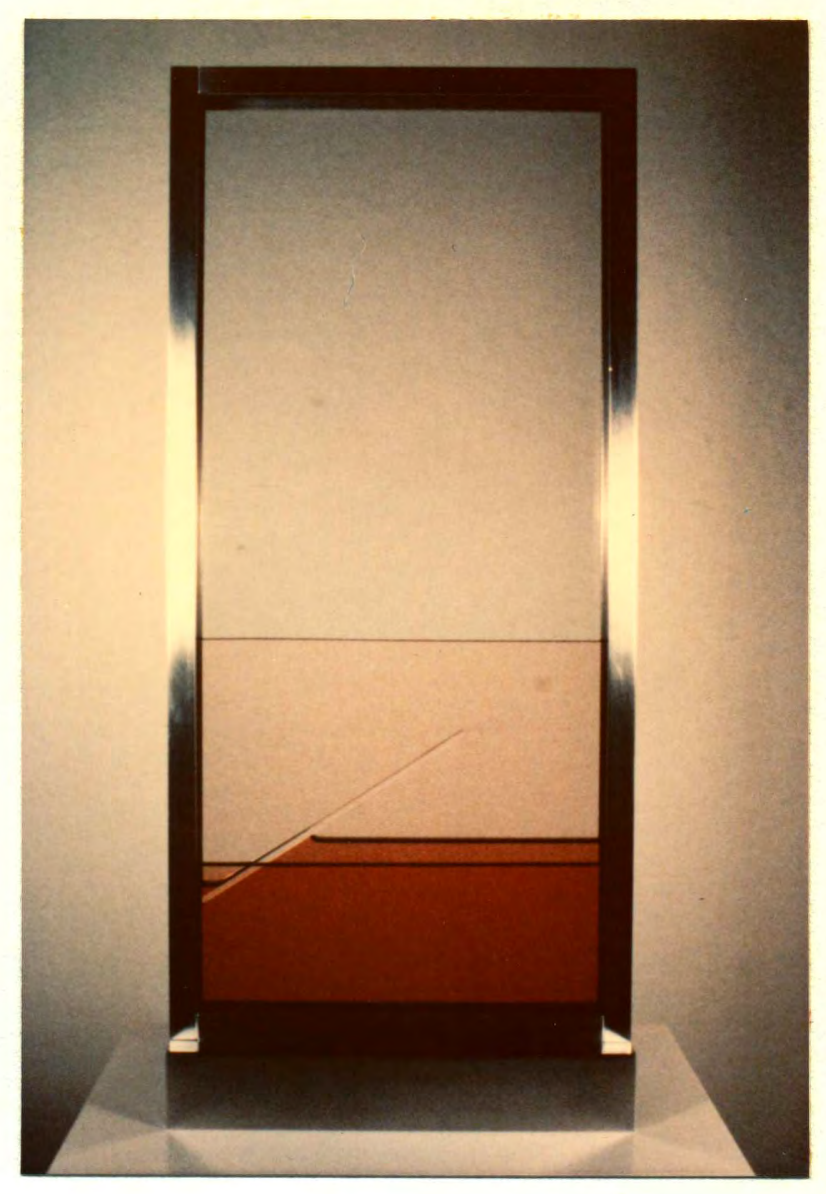

Figure 5

chambers, with its lighter color, followed (as the oil flowed through small holes connecting the chambers and hidden from view). I found this sculpture, and what it did, appealing; it was elegant, yet very simple. The shapes made by the oil and framed by the channel were just three rectangles, one above another, of slightly different value and hue. I debated whether or not I should leave the sculpture in this simple, perhaps one could say minimal, state. Finally I realized I could augment the sculpture by making a strip out of clear plexiglas which would be a variation of a "V" shape and would be just the right thickness to slip 
down between the pieces of plexiglas of the thicker middle chamber. The result was a plexiglas line coming up diagonally out of one of the aluminum sides. As the oil level rose there was, because of the line, a triangular area that could not fill. Finally the oil flowed over the upper edge of the strip and filled the triangular area. Then as the oil level dropped, a triangular area containing the oil was left above the level of the receding oil. In order for this process to repeat itself time and time again I drilled a small hole in the plexiglas strip so that the triangular area could slowly drain (Fig. 5-8).

I was pleased with these results, for now there was both a triangular shape and rectangular areas. There was also an aesthetically delightful quality in the way the triangle filled with oil. It seemed that the sculpture, which was very simple before, now had an appropriate degree of complexity to it.

I realized that there were many, many ways I could make shapes, within the rectangular aluminum format, that would hold or exclude the oil as it moved up and down. I felt I should make another piece, exploring these possibilities. I was mildly exuberant, for I realized that even if I made quite a number of pieces I would still be exploring possibilities. In any event, the fifth piece in the project was such a piece, broader than the sculpture described above, and more complex in the nature of the shapes and the way the oil moved between them (Fig. 9). 


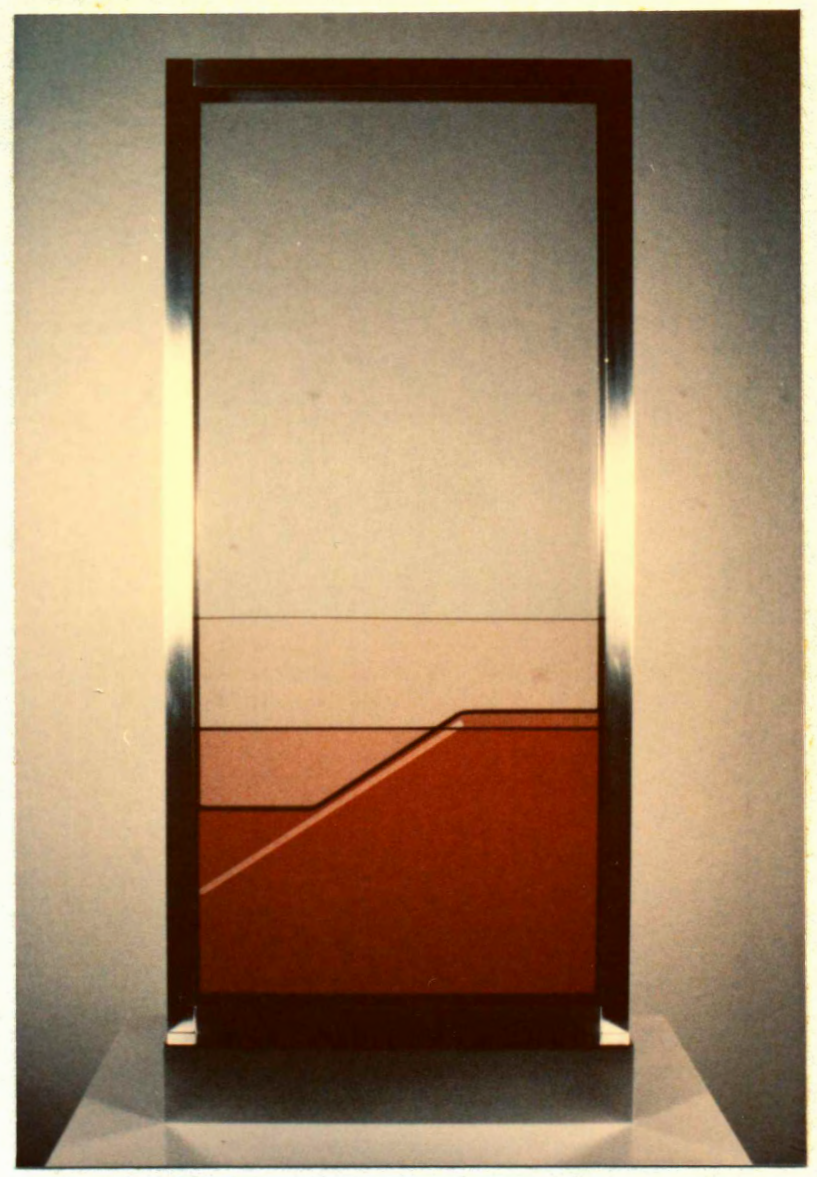

Figure 6 


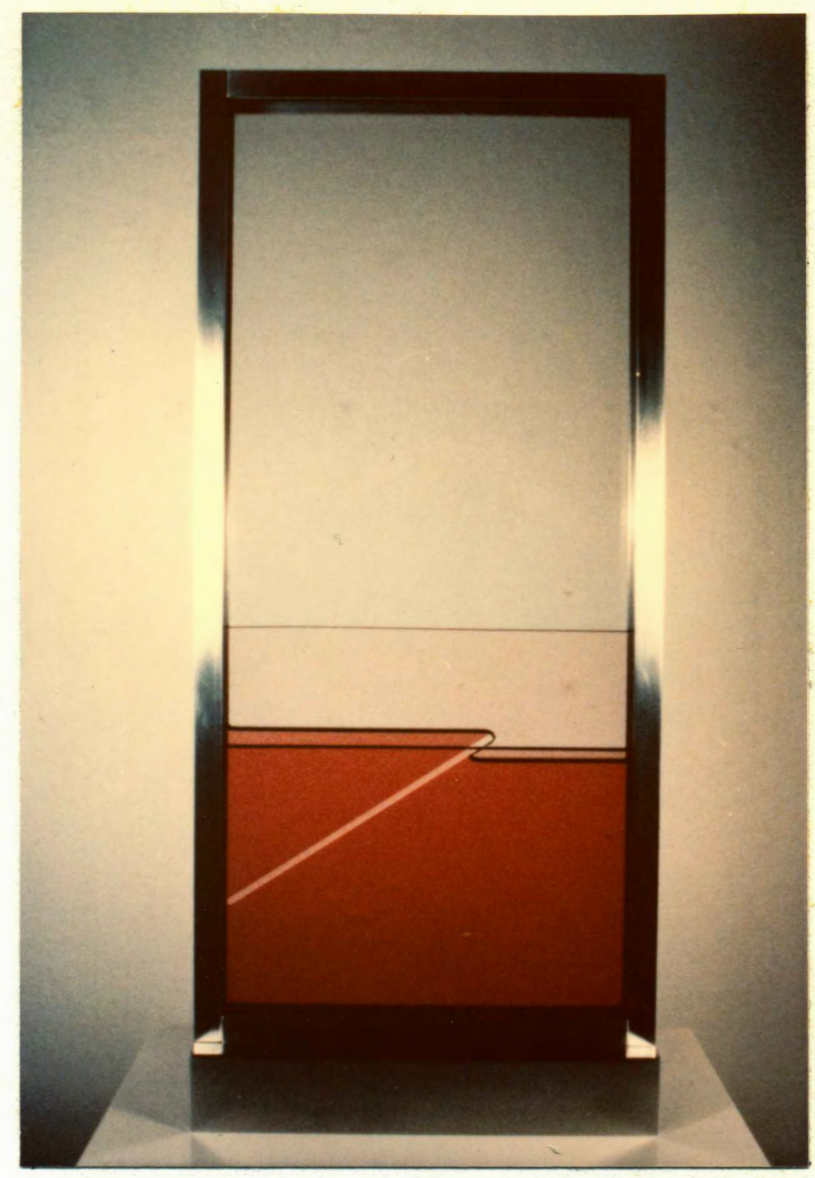

Figure 7 


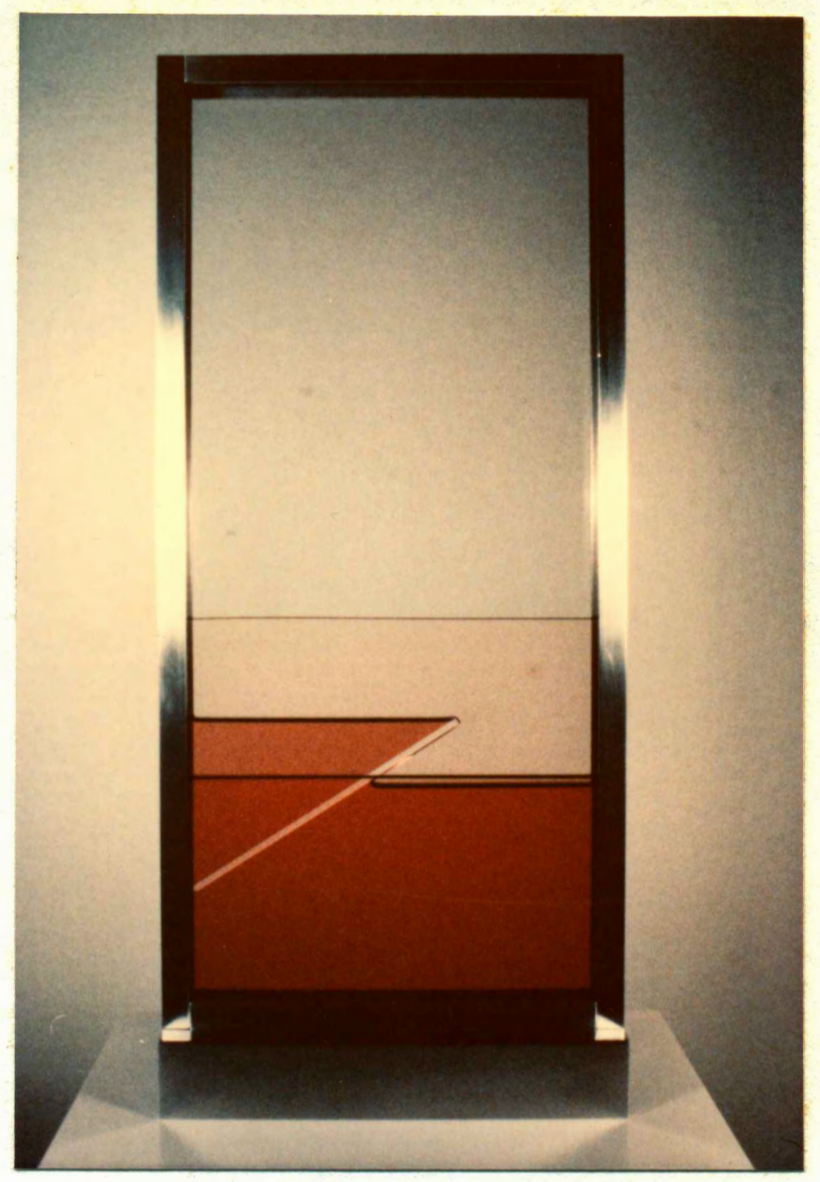

Figure 8 


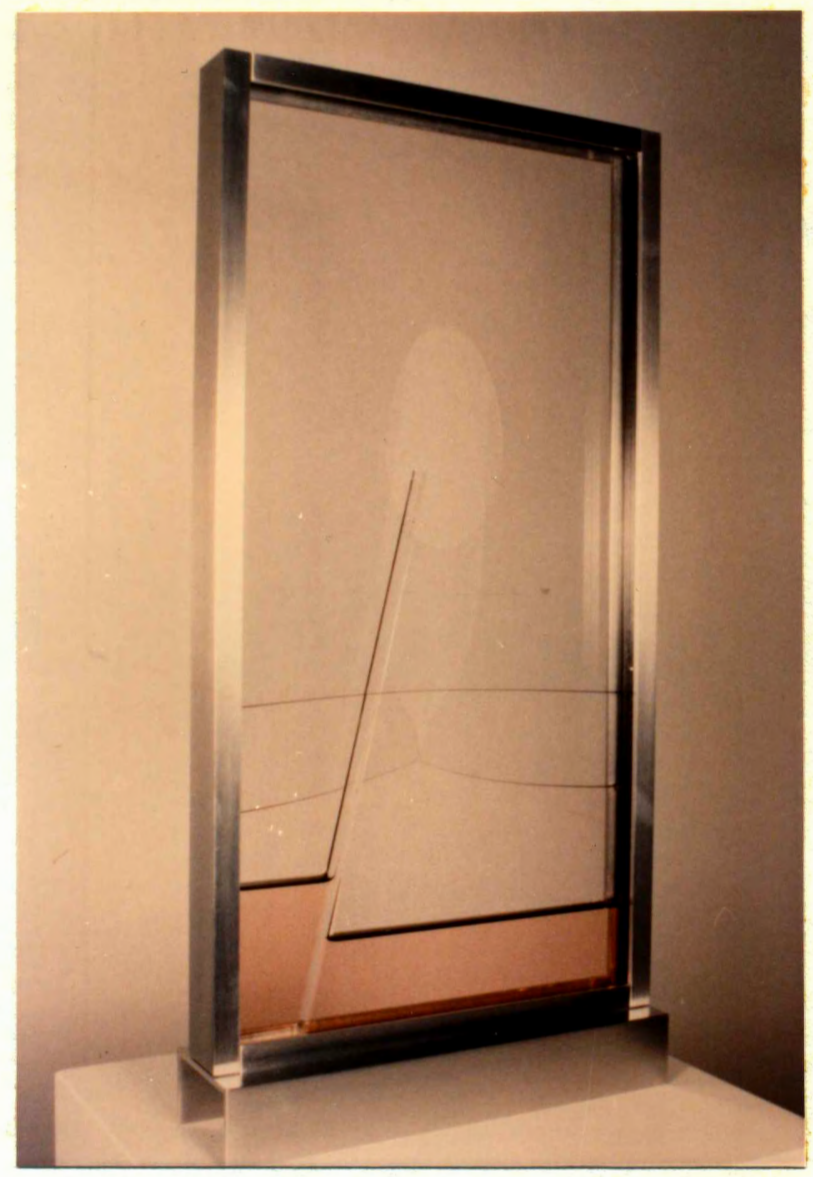

Figure 9 
THE DEVELOPMENT OF THE SCULPTURE STANDS

The height at which each sculpture was positioned was an important consideration. I found 45 inches to be a good height for the stand, a decision no doubt unconsciously affected by my own height. The sculptures are fairly small, either $171 / 2$ inches or $191 / 2$ inches high, and they need to be raised to nearly eye level. However, if they are raised too high everything about them begins to appear odd. As in the sculptures, the proportions of the stands are very important. Forty-five inches appears to be the right height to me. Then there are the considerations of width and depth.

At this point I would like to mention that these sculptures have an undeniable frontal quality. Still, the views as one moves around them to the side can give a fair degree of interest. The end view certainly is the least interesting, and might be described as austere or very simple. In a sense, to work with color and to place colored planes one in front of another demands this frontality. That is, to limit the complexity in the pieces enough so that I am more or less in control of what happens visually leads me to place the volumes parallel to one another, which in turn gives rise to the frontal quality. Perhaps at a later date when I have more thoroughly mastered this way of working I will be able to place volumes at other angles so that the pieces will not have such a definite sense of "front."

The stands have a double function: they raise the 
sculptures to viewing height and they contain pumps, timers, wiring, etc. Also, the sculptures must be far enough from the wall so that they do not cast a shadow on it as this would darken their color and produce a confusing situation visually. As well, a very real problem is where to put these pumps and timers. They have solved a set of problems as they have eliminated the set of auxiliary chambers and the dangling, swaying tubing, but now they must be housed somewhere. By far the easiest solution technically is to place them as close to their respective sculpture as possible. The bases are built with the paramount idea that they be as unobtrusive as possible. They are a simple rectangular shape. The idea that they taper slightly upward has been rejected. Various tints of off-white are tested to help towards this end. As they blend with the sculpture itself, their slight color works with the rather delicate color of the oils, forming a single, whole idea with the sculpture. I have spent considerable time carefully sanding and painting them, so that their flaws are minimized, which further serves this end; there are few variations on their surface to "catch the eye," and in their own right they are to be as unnoticeable as possible.

The width of these stands is somewhat determined by the width of their respective pieces: there is a kind of "shoulder" concept, a certain distance on the top of the stand between the edge of the aluminum base of the sculpture and the edge of the stand itself that compositionally seems appropriate. 
The depth has been standardized at 10 inches in order to provide room to contain the apparatus as well as to provide some stability to protect against the stand toppling over. The problem is that although proportions seem very good with a frontal view, as one moves around to the side one becomes increasingly aware of the size of the stand, its volume and mass seem appreciably larger from a three-quarter view. This can be a problem with a variety of sculpture besides my own, I have noticed, where the piece itself has a base or stand that is integrated with it. From the threequarter view the base seems too large. With each piece I have tried to arrive at the proportions for the stand that best suits the piece. However, I am aware that the piece as a whole is visually the most satisfying when seen from or nearly from the front. 
Small colored planes, the shapes of leaves, hang from their branches, arrayed one behind another, moving away endlessly into deepening space. Partially transparent, they catch the light, their hue intensifies, their colors add. They and all the other elements of the natural world, the world of the woods, form a complex spacial arrangement of extreme beauty and subtle movement. To approximate this world, or a small part of it, in a work of art, or to respond to it somehow, seems a reasonable goal or perhaps a compelling one.

With these kinds of sources of inspiration the producing of works of art can take many forms. My aim has been to capture something of the delicacy, transparency, and spacial density of small forms as well as the rather random structure of leaves on trees and bushes, and even undulations, perhaps only sensed, in the ground itself, all visual phenomena of an untended natural environment. 


\section{LITHOGRAPHY AND WATERCOLOR}

Lithography has turned out to be a way of working that allows me to realize some of these aspirations concerning the natural world (Figs. 10-19). It is possible to draw on the aluminum plates in a very spontaneous, immediate way. This is also true in the application of tusche washes, strokes or blobs of varying value and shape. It is further possible to overlay press runs of different colors, so that quite a great deal of color results, with some effect of transparency and spacial density as the various strokes or marks cluster together and overlap. In the prints I have tried to let a certain amount of randomness enter in, to let the print grow on its own, somewhat uncontrolled; I do not usually know the effect of a certain plate on the print itself until I have printed it. It is intended that the haphazard, invigorated strokes hover and dance in a way that corresponds to multicolored leaves densely arrayed on branches.

My involvement with lithograpy as a way to respond to the natural world then brought about a revitalization of an interest in watercolor that was years old (Figs. 20-21). Watercolor is, of course, a more direct medium than lithography. It is possible to have a finished piece after a couple of hours' work. This in itself is truly refreshing after one has worked months on a sculpture and still does not have it functioning properly. While results come quickly with watercolor these results tend more readily to have an impressionist 


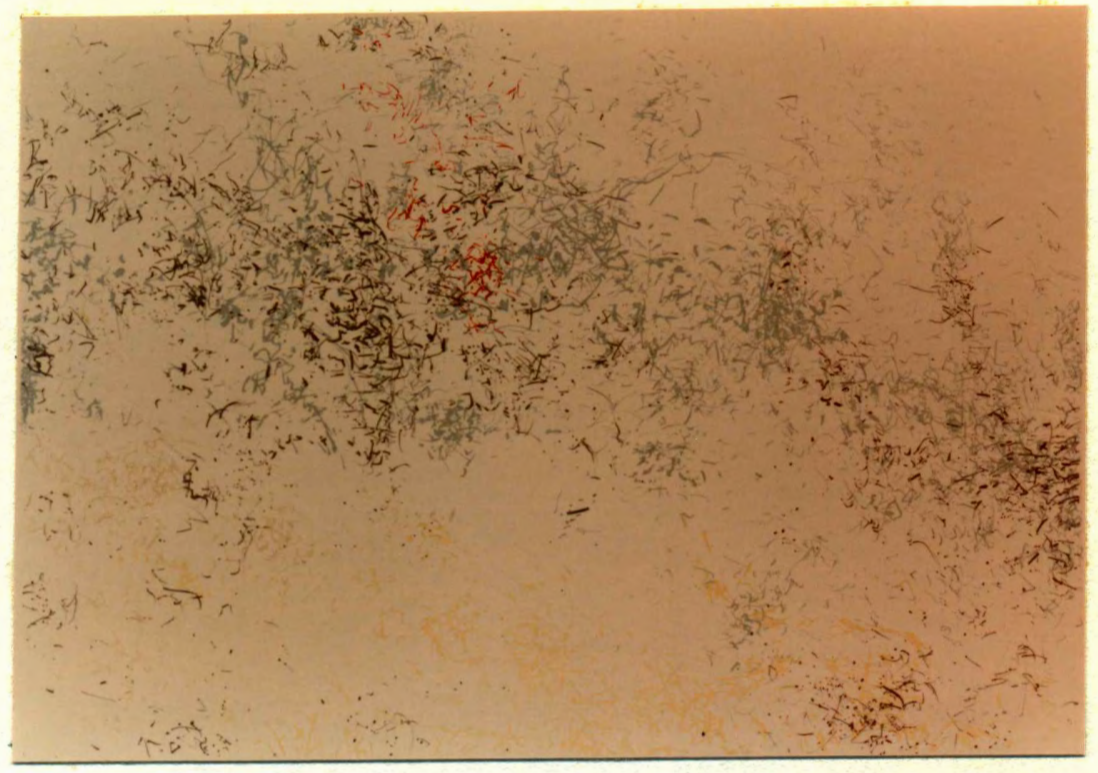

Figure 10

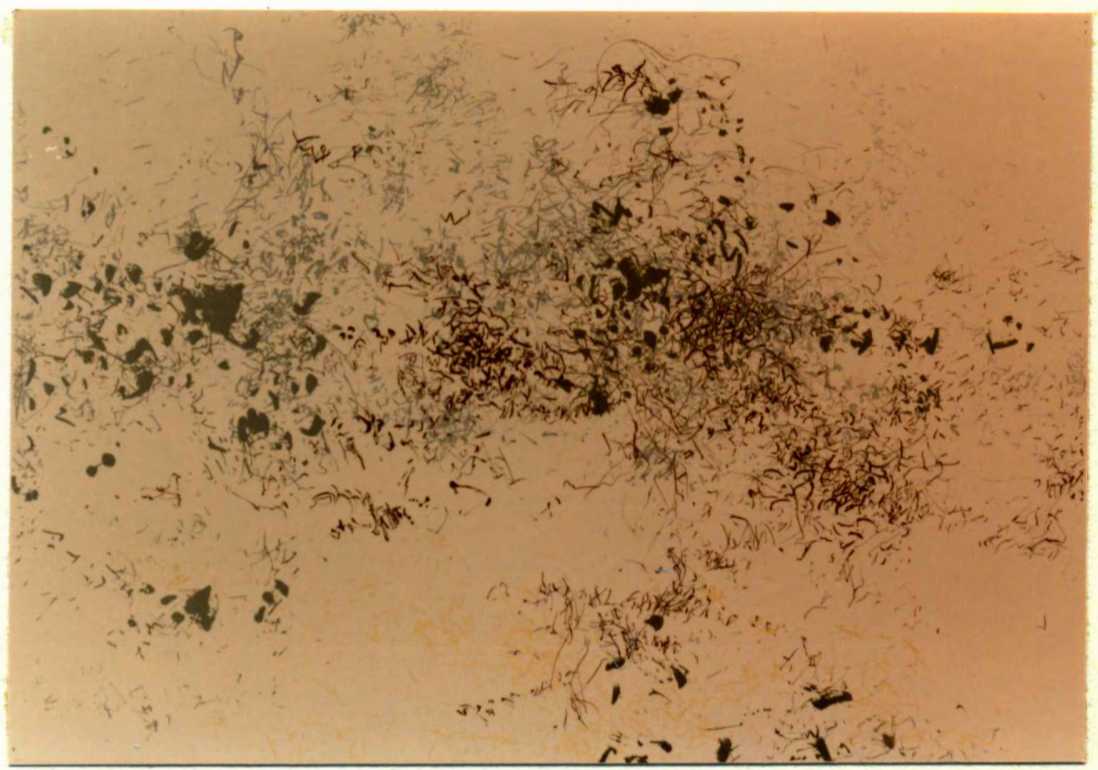

Figure 11 


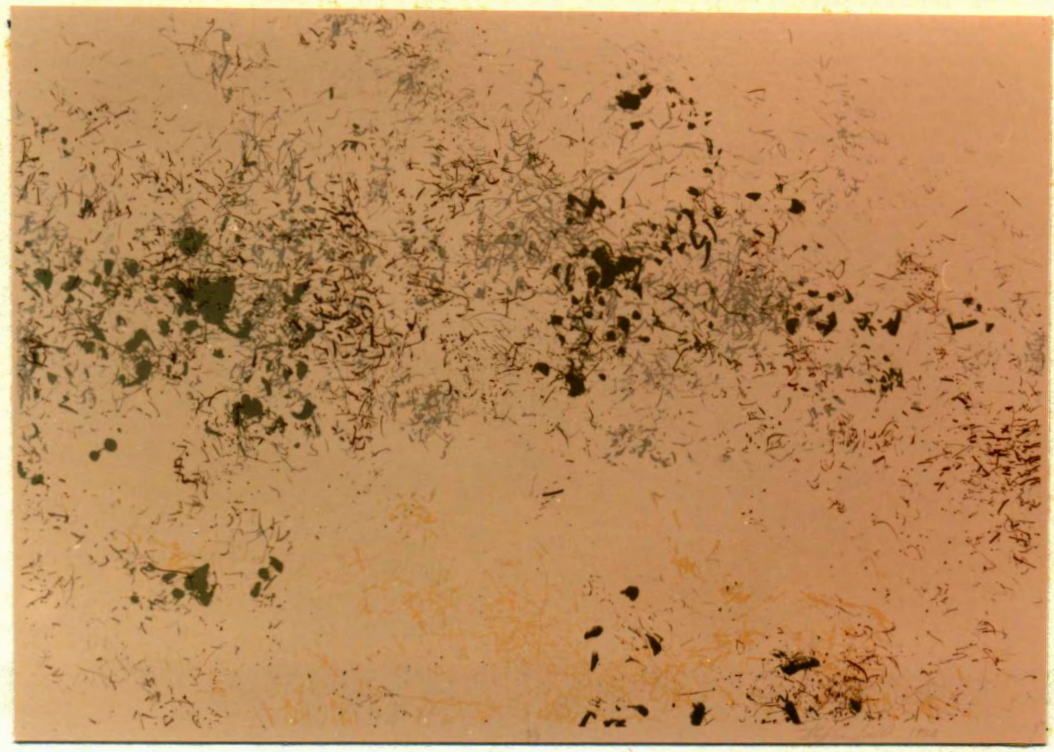

Figure 12

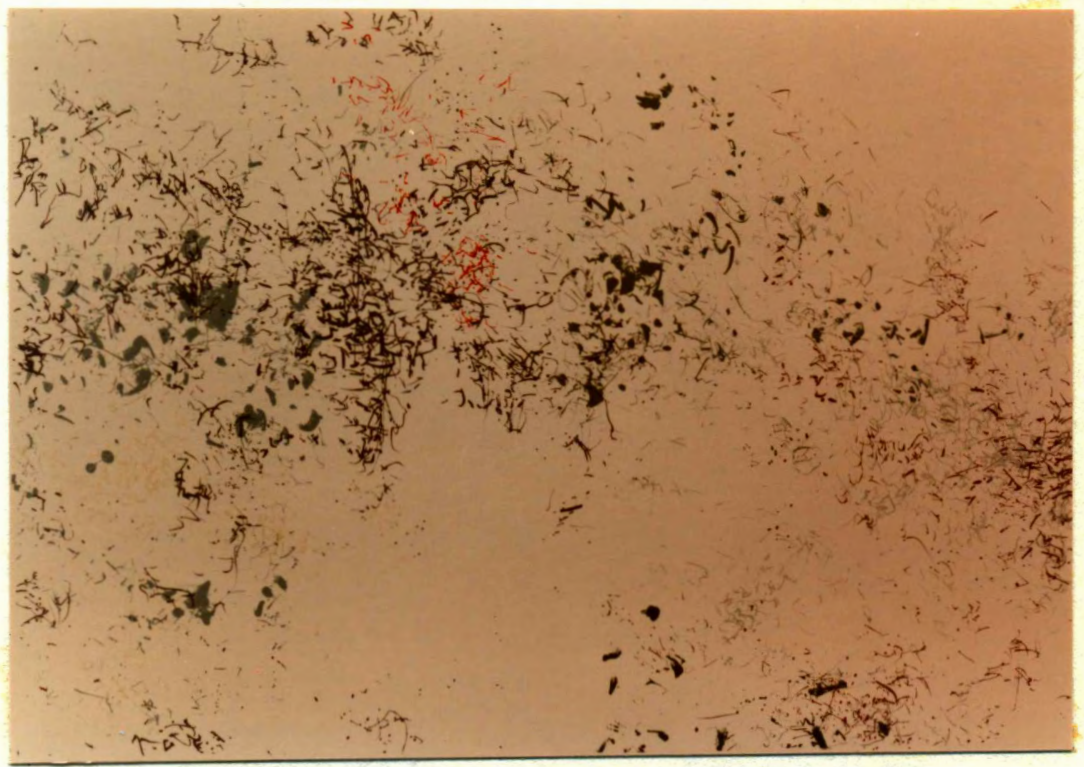

Figure 13 


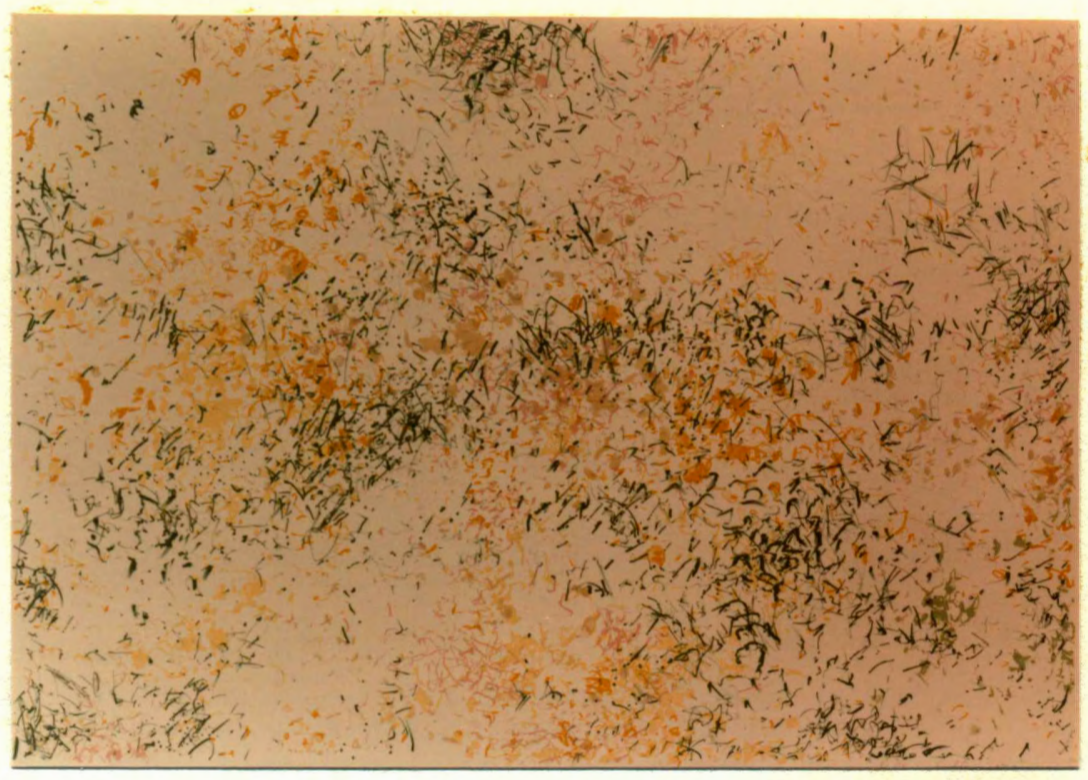

Figure 14

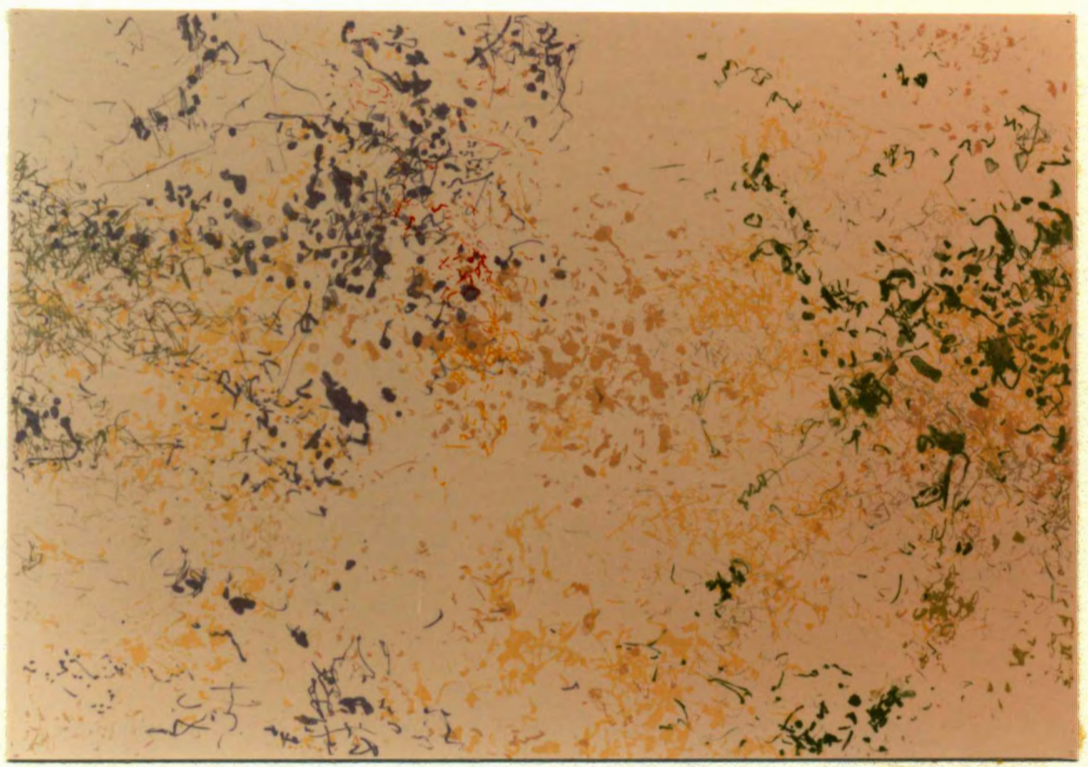

Figure 15 


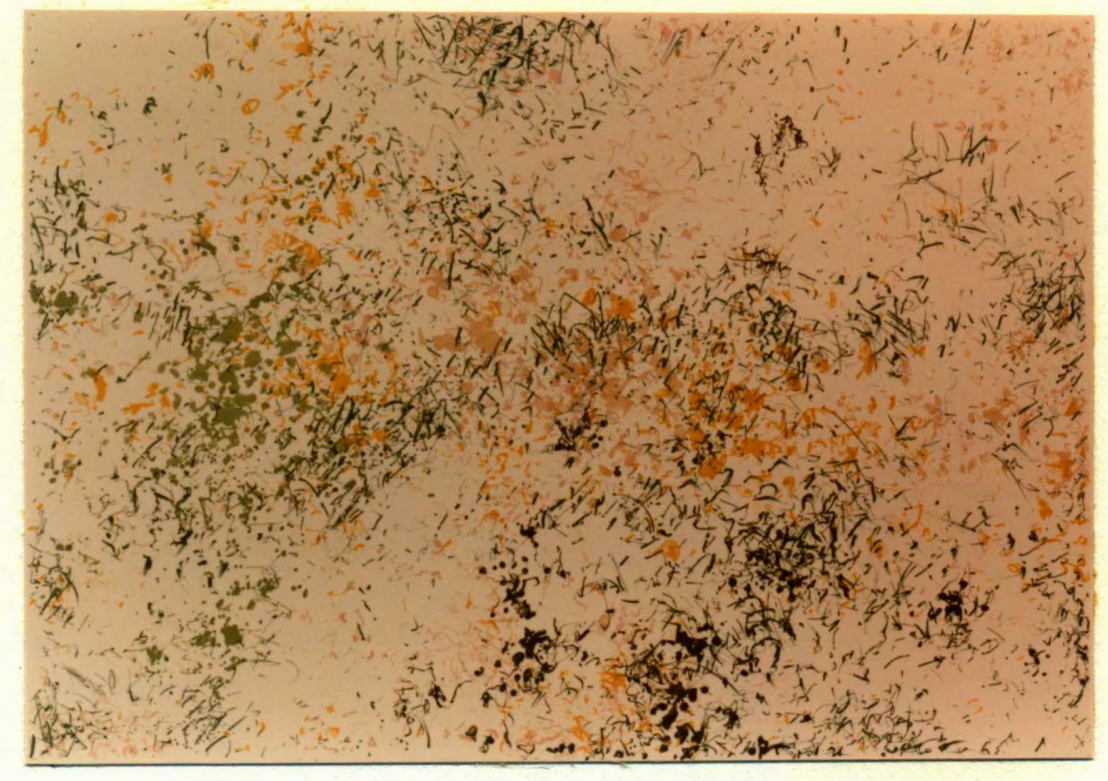

Figure 16

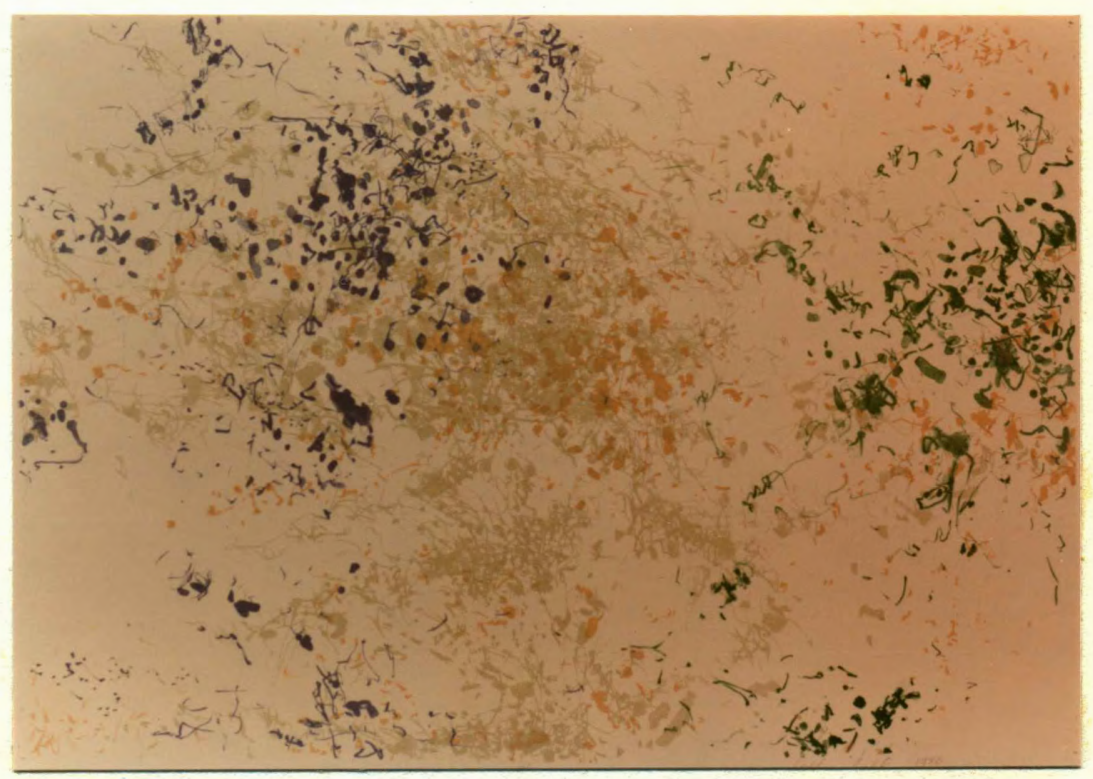

Figure 17 


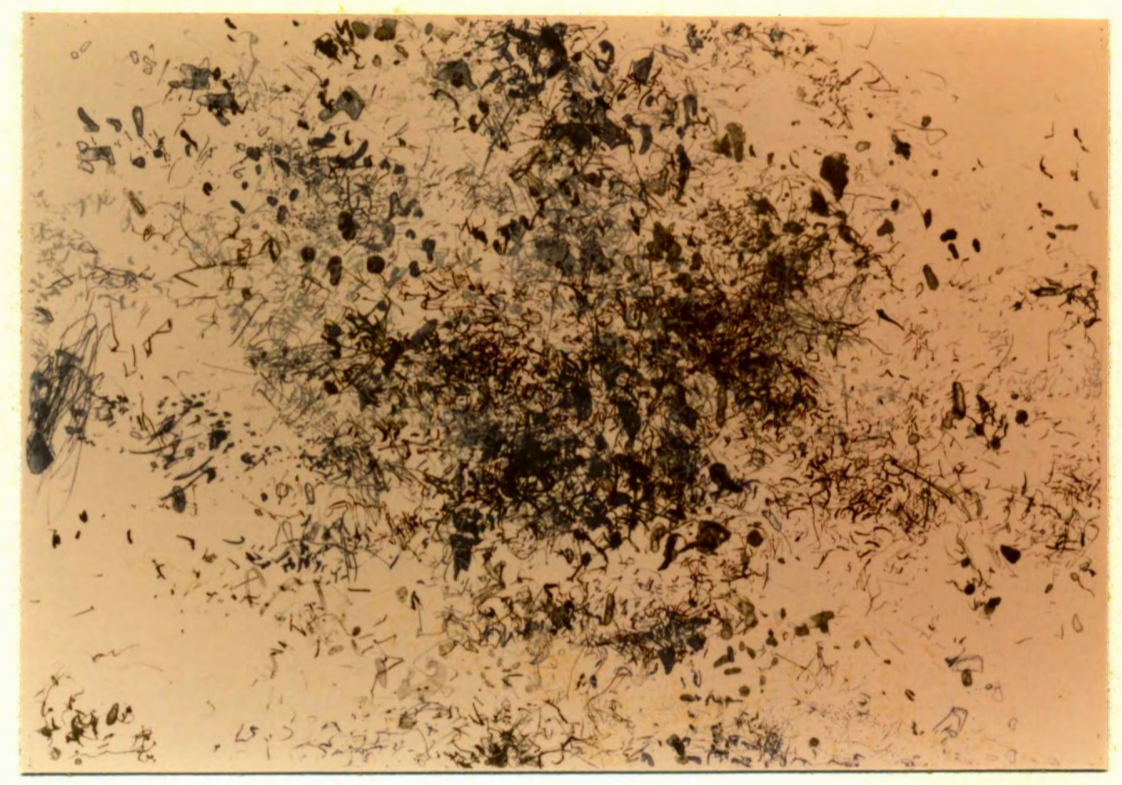

Figure 18

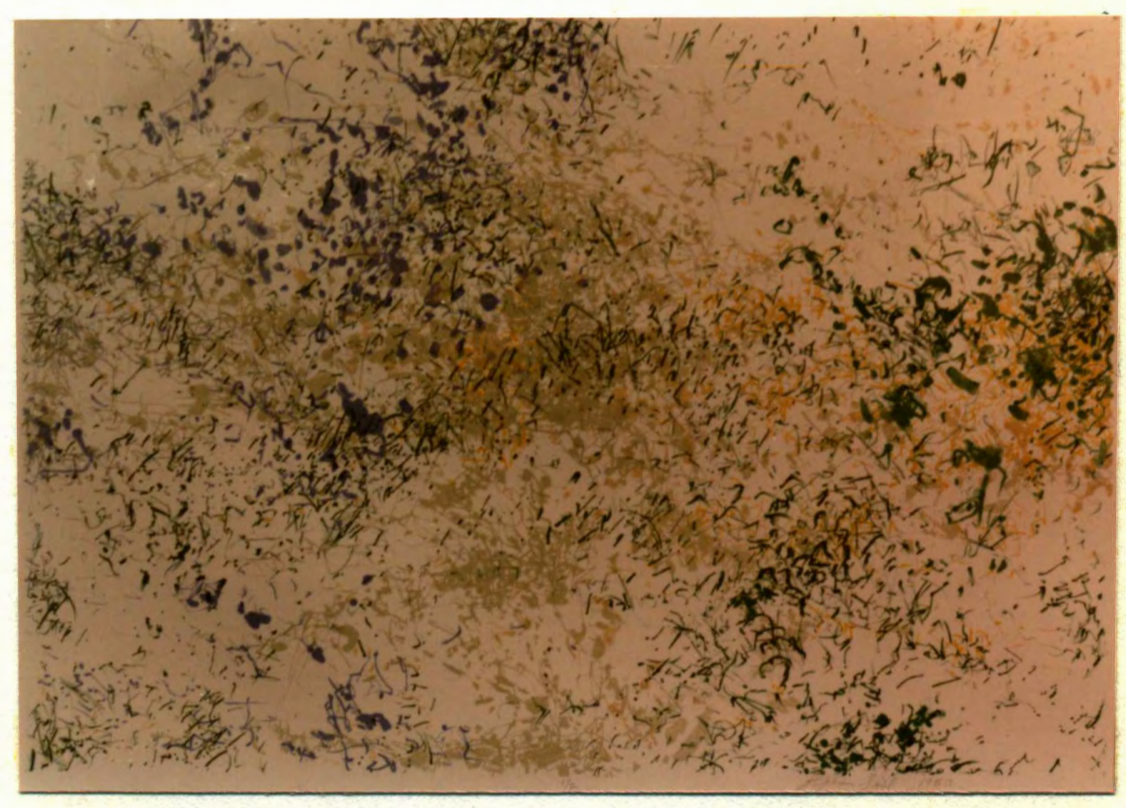

Figure 19 


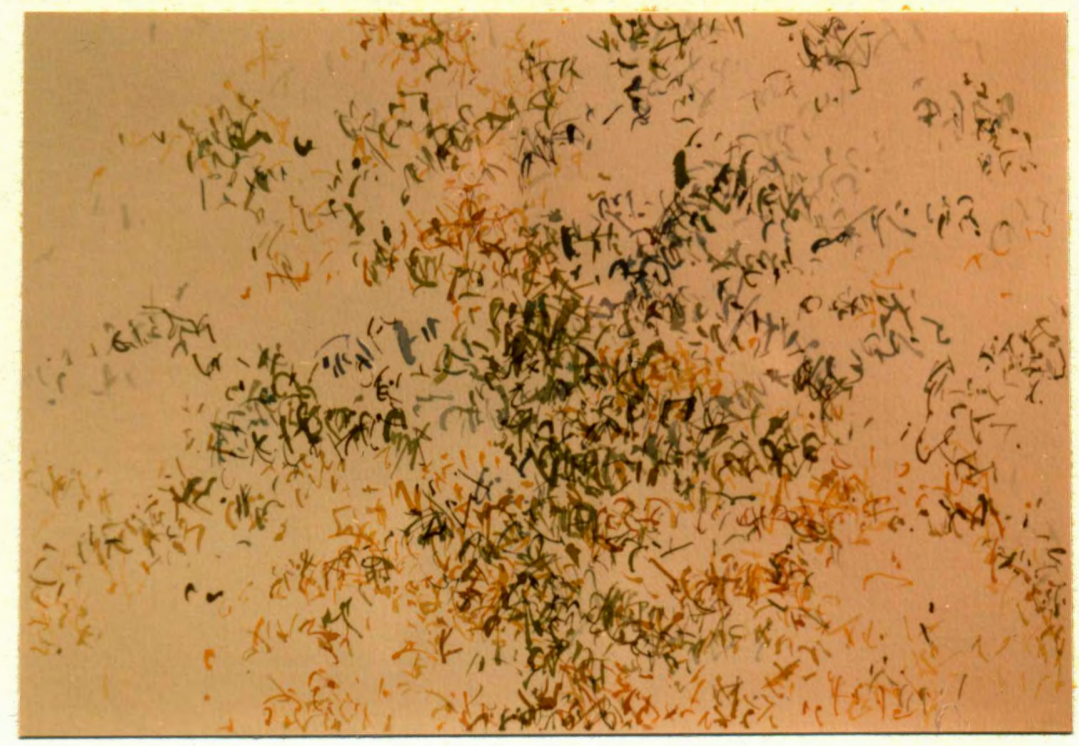

Figure 20

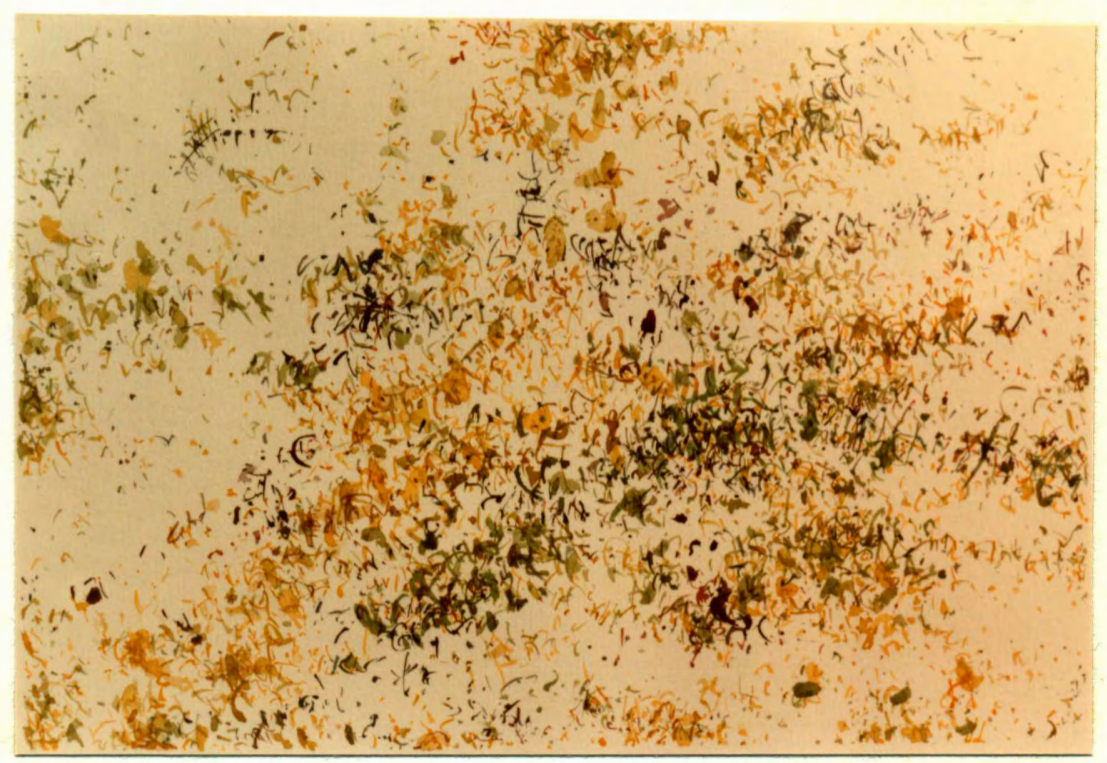

Figure 21 
look to them. The randomness that occurs in my approach to lithography, the somewhat uncontrolled and unexpected results that come about when various plates are overlaid, this has a more modern or up to date feeling for me, as it makes a break with traditional methods to some extent, and seems like a more valuable way for me to work in the future. In any event my interest in both lithography and watercolor is a result of the need to respond to the random but stunning beauty and inscrutable order of the natural world. 


\section{CONCLUSION}

One wonders now how much the sculptures have to do with the forms and phenomena of the natural world. There must surely be interconnections, ideas in common between the ideas about the sculptures as well as the ideas forming the basis for the lithographs and watercolors and the thoughts and feelings I have when actually out in the woods. Some of these influences on the sculptures I am only lately becoming aware of after having thought about these issues for the past couple of years.

In the first place how would one characterize the sculptures, what kinds of ideas and visual sensations do they communicate to the viewer? They certainly have a sense of extreme cleanness, a feeling of formality, control, perhaps restraint. The aluminum channel running up vertically has a thinness, hopefully a delicacy and gracefulness, but also a clarity and shiny hardness, a metallic quality. The channel provides structure, the supportive framework upon which all else is based. It orders, formalizes, composes.

The channel makes shapes, whose surfaces are plexiglas, which become smaller, greater in number, and more complex when the volumes fill with oil. Now there are planes or plates of pure, even color, rectangular, or trapizoidal. The transparent shapes overlay, the colors intensify and add. But the use of color is restrained, perhaps only two colors per sculpture, with their resulting additive colors. 
As one moves around the sculpture the vertical lines of the channel shift relative to each other, the parallax effect, making other shapes. Kineticism comes about, but not unlike that which is usual for all sculpture.

The oil rises and falls slowly, almost imperceptibly at times, in the chambers. Again there is a sense of control, restraint, quiet undulation. The quality of the kinetic is important. The oil is seen to be moving as one watches the sculpture, but it is more important that the sculpture is different each time the viewer returns to it.

The small shapes of pure color overlap in a manner distantly reminiscent of the watercolors of Cezanne, although as twodimensional works these watercolors contain an illusion of space whereas the sculptures attempt to deal with space in actuality. I must confess a great lifelong admiration for Cezanne's work and for his method of exploring the world out-of-doors. In his watercolors particularly one is aware of the small, separate, partially transparent shapes that overlap, sometimes many times, shapes which are, in fact, the individual brushstrokes. The work of Morris Louis also comes to mind, specifically the Veil paintings. However, here many layers of thin color have been poured over each other, merging in a very complex way and suggesting a space atmospherically very dense.

The way in which the channel provides structure is, of necessity, very geometric; that is, the regularizations and the predictability of the resulting forms are extreme. The 
tilted line or diagonal introduced into a sculpture is a first step away from this regularization of man-made forms and a step back towards the multiplicity and random quality of forms in the natural world. Since the lithographs and watercolors are a more obvious representation of this world, the tilted line within a sculpture makes for an initial formal link between the sculpture and the lithographs and watercolors.

In the sculptures there is an emphasis on precision, the rightness of forms, good proportions, fine craftsmanship. These are the goals; whether or not these pieces succeed the viewer may judge. There is the concept of perfect surfaces, surfaces uniform, unmarred, shiny. These surfaces are industrially produced, the products of present day technology, surfaces I attempt to leave alone, cutting and filing and polishing only the edges. For me they correspond to the perfection, the purity of surfaces found in nature. I think of moss, fresh and bright, growing on rocks or in cracks in the pavement. I think of water in a stream flowing over rocks, a thin, even layer, clear, reflective, perfect.

For me these sculptures are a positive response to the natural world, an affirmation, an attempt to augment or slightly add to the heritage of the world. And the lithographs and watercolors have the same purpose, but their means are different, and they communicate in other ways. The vertical lines of the sculptures are like trees, structuring, ordering. Surely the columns of Greek temples were a 
reference to trees, clustered together in a grove, forming a sacred or special place. There also must have been such a reference for Gothic cathedrals, piers rising up and spreading into arches, tracery, like branches and vines, everywhere.

Especially my response has been to leaves, multicolored, suspended, forming a complex, active, dense space, moving slightly minute by minute, changing color and falling as the seasons change. Here the small shapes holding the oil correspond, overlapping with subtle color changes, arranged behind one another in rows, attempting to form a more complex space. The small shapes in the lithographs correspond as well, and perhaps would be, in a sense, more easily identifiable with the shapes of leaves.

of course the sculptures are very simple compared to the visual complexity of the natural world. Technical problems have to be mastered. Indeed these problems have brought about an extreme sense of frustration for me. But perhaps these pieces are only a first step: greater complexity and sophistication will be possible as technical difficulties are worked out.

The quality of light these pieces have, due to their reflective surfaces and their transparencies, is a significant aspect of them, and, I hope, leads to a spirit of contemplation. They may be likened to a pleasant spacing of thoughts within an unhurried context. While they appear visually as pure abstract form, they might arouse emotions, 
perhaps unspecified, or might give rise to intense feelings within an overall condition of calmness. 